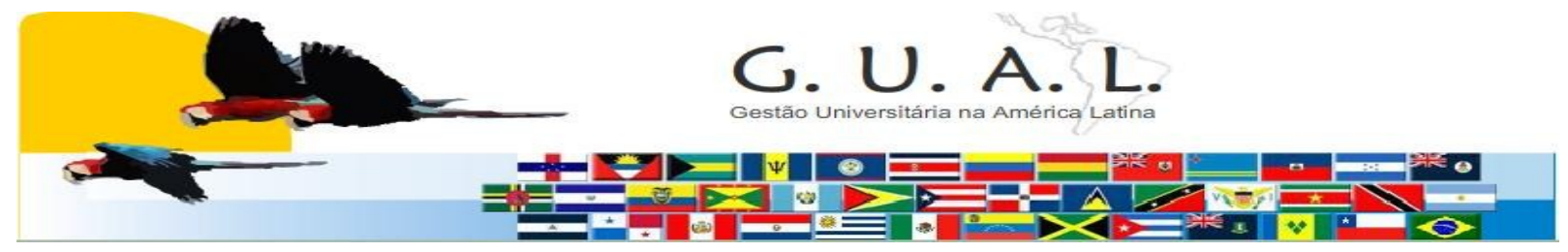

ISSN 1983-4535

\title{
GESTÃO INTEGRADA DE RESÍDUOS SÓLIDOS PARA INSTITUIÇÕES PÚBLICAS DE ENSINO SUPERIOR
}

\author{
Dante Luiz Juliatto, Doutor \\ Universidade Federal de Santa Catarina \\ dante.juliatto@ufsc.br \\ Milena Juarez Calvo, Bacharel \\ Universidade Federal de Santa Catarina \\ milenajuarez@hotmail.com \\ Thaianna Elpídio Cardoso, Bacharel \\ Universidade Federal de Santa Catarina \\ thaiannacardoso@gmail.com
}

\begin{abstract}
RESUMO
Este texto apresenta uma discussão a respeito da problemática resíduos sólidos frente à recente Lei Federal 12.305/2010, quanto à proposta de instrumentos para a gestão em Instituições Públicas e como tem se dado este enfrentamento em Universidades Públicas e órgãos de sua administração. Tem-se como objetivo a proposta de uma sistematização de procedimentos integrados, a partir de uma visão complexa desta realidade específica. A realização do estudo de caso na Universidade Federal de Santa Catarina culmina para consolidação de um modelo de gestão, que venha ajustar às legislações vigentes, possibilitando a sua adaptação à cultura da sustentabilidade. Para isto, aborda-se o papel fundamental das universidades como laboratório de idéias na constante busca por soluções, aliada às demais leis para o desenvolvimento sustentável.
\end{abstract}

Palavras-chave: Gestão integrada. Resíduos sólidos. Instituições públicas. Universidades. 


\section{INTRODUÇÃO}

As pessoas, para realização de suas atividades, geram uma série de resíduos. Porém, até antes da II Guerra Mundial, estes resíduos eram de composição mais simples, basicamente orgânica, e de mais fácil destinação e decomposição. Nas últimas décadas este quadro se modificou: é crescente geração de resíduos e a sua evolução quantitativa. A geração per capita de resíduos está diretamente relacionada ao consumo exagerado, rápido crescimento populacional e seu adensamento espacial. A evolução dos materiais empregados pelas sociedades, acompanhando o modelo de industrialização iniciado na Revolução Industrial (FIGUEIREDO, 1995), vem tornando cada vez mais complexo o tratamento e destinação final destes resíduos.

Embora, a produção de resíduos seja inerente à atividade humana, a relação entre um e outro é conflituosa. A sociedade, de uma forma geral, sempre se relacionou com seus resíduos por meio de atitudes de afastamento, alienação, preconceitos e estigmas (PORTILHO, 1997).

Diante da situação, o cenário fica cada vez mais preocupante, pois vemos a acelerada degradação do ambiente, comprometendo a qualidade de vida (LIMA, 2004). Em termos ambientais, a disposição inadequada do lixo pode contribuir para a poluição do ar, das águas, do solo, bem como promover impactos negativos sobre a fauna e flora dos ecossistemas locais, além de ser responsável por questões estéticas que comprometem o bem-estar das pessoas. Além disso, em termos sociais, a disposição descontrolada de resíduos sólidos traz como consequência, o surgimento de pessoas em busca do seu valor econômico, efetuando a reciclagem informal, expondo-se aos riscos de acidentes com materiais perfuro cortantes e ao contato direto com resíduos infectantes e/ou perigosos.

Diariamente a situação se agrava e fica mais difícil a solução, visto que, áreas adequadas para abrigar sistemas de disposição final estão escasseando. É grande a preocupação existente com a saturação dos aterros sanitários, com a contaminação do lençol freático e com o impacto resultante do consumo desmedido de recursos naturais. No Brasil a situação do manejo de resíduos sólidos, não deixa de ser preocupante, principalmente no que diz respeito a esta questão da disposição final, dados da Pesquisa Nacional de Saneamento Básico (IBGE, 2008) indicam que 50,8\% dos municípios brasileiros utilizam lixões como 
forma de disposição dos resíduos sólidos urbanos, e 27,7\% dispõem os resíduos em aterros sanitários.

Pesquisas indicam que uma das dificuldades existentes no trato do problema está no fato de que os resíduos sólidos apresentam uma questão particular, percorrem um longo caminho - geração, descarte, coleta, tratamento e disposição final - e envolvem diversos atores, de modo que o tratamento meramente técnico tem apresentado resultados pouco animadores.

Em regiões mais industrializadas como, por exemplo, a Europa, tratar enormes quantidades de resíduos, ou melhor, evitar que estes sejam gerados, tem sido um dos focos centrais de políticos e legisladores (RAMOS,1998). Considerando as tendências mundiais, a pressão por um ambiente mais equilibrado, para a consolidação de uma nova realidade socioambiental para o enfrentamento do problema dos resíduos sólidos, faz-se necessário reunir esforços para o conhecimento de medidas que minimizem a sua geração.

Neste cenário, a melhoria do desempenho ambiental na administração pública é considerada um tema chave, uma vez que em seus diversos setores são importantes agentes econômicos, consumidores de bens e serviços, e também geram, no exercício de suas funções e atividades, significativos impactos ambientais. A contribuição e o exemplo que os governos podem dar para que se promova a mudança dos atuais padrões de consumo da sociedade, a adoção de processos de produção mais limpas, assim como a não indiferença a problemática dos resíduos sólidos é relevante e não deve ser desprezada. A promoção do entendimento e a internalização das questões ambientais no dia-a-dia das atividades das pessoas deve ser estimulada, e aos governos atribui-se papel estratégico na indicação dos novos referenciais, sendo fundamental o comprometimento por parte da alta administração das instituições governamentais.

Compondo esta esfera da administração pública, as Universidades destacam-se no que concerne o ensino, a pesquisa e a extensão como uma nova perspectiva na busca por soluções. Uma vez que herdam as mesmas dificuldades dos diversos setores da administração pública referentes à sua operação, além da mesma necessidade de infraestrutura básica que contemple inclusive, um saneamento efetivo dos resíduos gerados, possibilitando a comparação dos campi a núcleos urbanos. Ainda sim, tem-se nesses espaços a oportunidade de implementação de estratégias modelos e exemplos de melhores práticas direcionadas ao desenvolvimento 
sustentável, todavia, reconhecem-se peculiaridades da dimensão universitária, dentre as quais é possível salientar a sazonalidade e tendência cosmopolita dos cidadãos universitários, o que resulta em uma falta de pertinência com o território normalmente não evidenciado em cidades tradicionais.

\section{CONTRIBUIÇÕES TEÓRICAS}

A implantação do gerenciamento de resíduos sólidos visa a formulação, avaliação e gestão de políticas públicas para o tratamento adequado do lixo. Para que a intenção da implantação de gestão se torne compromisso é preciso que as pessoas que fazem parte de todo o processo entendam alguns termos e políticas já estabelecidas. O conhecimento das leis e da importância de ajudar na melhoria da qualidade ambiental da instituição faz com que os participantes incorporem os critérios da gestão ambiental, direcionada pelos conceitos preconizados de uma Política, em suas atividades através do engajamento individual e coletivo e da mudança de hábitos.

\subsection{Política ambiental}

A Política Ambiental constitui o conjunto de diretrizes e princípios que devem nortear a definição e a aplicação de instrumentos legais e institucionais de planejamento e gerenciamento ambientais. Os instrumentos, definidos conjuntamente pelo Estado e pela sociedade, têm como finalidade trabalhar as tendências econômicas e sociais com vistas a viabilizar a realização do desenvolvimento sustentável (TEIXEIRA, s/d).

Segundo ALMEIDA (2000), é de fundamental importância a sua formalização, pois expressa o pensamento, a visão e o comprometimento da instituição com o meio ambiente. Torna-se necessário que a política ambiental seja compatível com outras políticas e normas internas da organização para se obter uma melhoria contínua do seu desempenho ambiental. O autor ainda afirma que a Política Ambiental trata de um compromisso com a melhoria contínua do desempenho ambiental da Instituição, através da implementação de um sistema de gestão com metas de melhoria definidas. É compromisso de toda instituição reduzir os impactos ambientais nos processos, produtos e serviços e certificar a contratação de fornecedores e prestadores de serviços que também tenha o mesmo comprometimento. 


\subsection{Gestão ambiental}

Entende-se por gestão ambiental (MORENO \& POL, 1999) aquela que incorpora os valores do desenvolvimento sustentável na organização social e nas metas corporativas da empresa e da administração pública. Integra políticas, programas e práticas relativas ao meio ambiente, em um processo contínuo de melhoria da gestão. Busca a maior eco eficiência aplicada as melhores e mais limpas tecnologias disponíveis. Prioriza a minimização de geração de resíduos, a reciclagem, a reutilização e a disposição final adequada.

O desenvolvimento de um sistema de gestão ambiental exige em primeiro lugar a adaptação a uma Política Ambiental que deve recorrer dos princípios de ação da organização, assumindo os compromissos e cumprimentos da lei ou normas que estão estabelecidas e regulam os comportamentos das pessoas, das sociedades, das empresas, das formas de produção e seus efeitos.

Na visão de SCHENINI (2005), a adoção de medidas ambientalmente responsáveis é motivada por razões internas e externas das organizações. Dentre as razões internas estão a diminuição de custos, a atualização tecnológica, a otimização nos processos produtivos e o desenvolvimento de uma cultura interna ecologicamente correta. No que concerne às razões externas estão a tendência à prevenção de acidentes ecológicos por parte da sociedade e as demandas das partes interessadas, principalmente de agências financiadoras, comunidade local, organizações da sociedade civil e governo.

Diante da necessidade de poupar matérias-primas e recursos, conservar energia e preservar o meio ambiente, torna-se imprescindível uma eficiente gestão de resíduos sólidos, a partir de um conjunto de ações, comportamentos e procedimentos que possuam como objetivo central, a minimização dos impactos ambientais, ligados à produção e à destinação do lixo.

\subsection{Resíduos sólidos}

Segundo a Norma NBR 10.004, revisada em 2004, a definição de resíduos sólidos é a seguinte:

"Resíduos nos estados sólido e semi-sólido, que resultam de atividades de origem industrial, doméstica, hospitalar, comercial, agrícola, de serviços e de varrição. Ficam incluídos nesta definição os lodos provenientes de sistemas de tratamento de água, aqueles gerados em equipamentos e instalações de 
controle de poluição, bem como determinados líquidos cujas particularidades tornem inviável o seu lançamento na rede pública de esgotos ou corpos de água, ou exijam para isso soluções técnica e economicamente inviáveis em face à melhor tecnologia disponível."

A NBR 10.004 ainda classifica os resíduos quanto aos riscos potenciais ao meio ambiente e à saúde pública. A classificação dos resíduos sólidos gerados em uma determinada atividade é o primeiro passo para estruturar um plano de gestão adequado. A partir da classificação serão definidas as etapas de coleta, armazenagem, transporte, manipulação e destinação final, de acordo com cada tipo de resíduo gerado.

ZANTA e FERREIRA (2003) definem resíduos sólidos como aqueles que são produzidos pelas inúmeras atividades desenvolvidas em áreas com aglomerações humanas do município, abrangendo resíduos de várias origens, como residencial, comercial, de estabelecimentos de saúde, industriais, da limpeza pública (varrição, capina, poda e outros), da construção civil e, finalmente, os agrícolas.

O gerenciamento inadequado de tais resíduos pode resultar em riscos indesejáveis às comunidades, constituindo-se ao mesmo tempo em problema de saúde pública e fator de degradação ambiental, além, dos aspectos sociais, estéticos, econômicos e administrativos envolvidos (SMA 1998b).

\subsection{Gestão integrada de resíduos sólidos}

Segundo MONTEIRO (2001), Gerenciamento Integrado de Resíduos Sólidos Urbanos é, em síntese, o envolvimento de diferentes órgãos da administração pública e da sociedade civil com o propósito de realizar a limpeza urbana, a coleta, o tratamento e a disposição final do lixo, elevando assim a qualidade de vida da população e promovendo o asseio da cidade, levando em consideração as características das fontes de produção, o volume e os tipos de resíduos - para a eles ser dado tratamento diferenciado e disposição final técnica e ambientalmente corretas -, as características sociais, culturais e econômicas dos cidadãos e as peculiaridades demográficas, climáticas e urbanísticas locais. Para tanto, as ações normativas, operacionais, financeiras e de planejamento que envolvem a questão devem se processar de modo articulado, segundo a visão de que todas as ações e operações encontram-se interligadas, comprometidas entre si.

Ainda, na visão do autor, o gerenciamento integrado focaliza com mais nitidez os 
objetivos importantes da questão, que é a elevação da urbanidade em um contexto mais nobre para a vivência da população, onde haja manifestações de afeto à cidade e participação efetiva da comunidade no sistema, sensibilizada a não sujar as ruas, a reduzir o descarte, a reaproveitar os materiais e reciclá-los antes de encaminhá-los ao lixo.

Para LIMA (2001), o modelo de gestão integrada de resíduos sólidos pode ser entendido como "um conjunto de referências político - estratégicas, institucionais, legais, financeiras, sociais e ambientais capaz de orientar a organização do setor”. São elementos indispensáveis na composição de um modelo de gestão:

- Reconhecimento dos diversos agentes sociais envolvidos, identificando os papéis por eles desempenhados e promovendo sua articulação;

- Integração dos aspectos técnicos, ambientais, sociais, institucionais e políticos para assegurar a sustentabilidade;

- Consolidação da base legal necessária e dos mecanismos que viabilizem a implementação das leis;

- Mecanismos de financiamento para a auto-sustentabilidade das estruturas de gestão e do gerenciamento;

- Informação à sociedade, empreendida por todos os setores, para que haja controle social;

- sistema de planejamento integrado, orientando a implementação das políticas públicas para o setor.

Para a aplicação da gestão integrada de resíduos sólidos (MESQUITA JÚNIOR, 2007), devem-se definir estratégias, ações e procedimentos que busquem o desenvolvimento sustentável a partir do consumo responsável, da minimização da geração de resíduos e da promoção do trabalho dentro de princípios que orientem para um gerenciamento adequado, com a participação dos diversos segmentos da sociedade, de forma articulada.

\subsection{Desenvolvimento sustentável}

$\mathrm{O}$ conceito - "O desenvolvimento sustentável é aquele que atende às necessidades do presente sem comprometer a possibilidade de as gerações futuras atenderem as suas próxima necessidades" - apareceu pela primeira vez em 1987, durante o desenvolvimento dos trabalhos da Comissão Brundtland, preparatória da ECO-92. O tema ganhou importante espaço nas representações sociais, sinalizando para a necessidade de articulações baseadas numa política 
ambiental e para a importância de haver regras e limites para a exploração dos recursos naturais.

De acordo com o Relatório de Brundtland (1991, p. 49), também chamado de "Nosso Futuro Comum", o desenvolvimento sustentável é um processo de transformação no qual a exploração dos recursos, a direção dos investimentos, a orientação do desenvolvimento tecnológico e a mudança institucional se harmonizam e reforçam o potencial presente e futuro, a fim de atender às necessidades e às aspirações humanas.

A aplicação do conceito à realidade requer, no entanto, uma série de medidas por parte do poder público e da iniciativa privada, buscando um alto nível de conscientização e de participação de ambos os lados. Os impactos ambientais causados, tanto pela utilização dos recursos naturais quanto pela modificação da paisagem e pela geração dos grandes volumes de resíduos exige que sejam seguidas diretrizes a partir de políticas que visam à implantação de um modelo prático de gestão.

\section{RESÍDUOS SÓLIDOS E SUAS ABORDAGENS}

A aplicação de um modelo de gestão requer o conhecimento da Lei que institui a Política Nacional de Resíduos Sólidos para que seja possível o alinhamento aos princípios e objetivos desta. No desenvolvimento do presente artigo abordaremos a gestão ambiental de resíduos sólidos em alguns setores públicos passando pelos municípios, instituições em geral e finalmente focando em universidades.

\subsection{A política nacional e os planos municipais de gestão integrada de resíduos sólidos}

Os benefícios de uma gestão integrada de resíduos sólidos urbanos são muitos. Podese destacar, por exemplo, a melhoria do aspecto estético de uma cidade, o auxílio na eficiência de outros setores do saneamento, a inclusão social nas fases de coleta e tratamento de recicláveis, o prolongamento da vida útil de aterros sanitários entre outros fatores determinantes para a qualidade de vida de uma população.

A Política Nacional de resíduos sólidos (PNRS), sancionada em 02 de agosto de 2010, através da Lei 12.305, é um novo marco na forma em que o tema vem sendo abordado, deixa claro seu desejo de impulsionar a busca por um modelo de gestão ideal ao trazer em seu texto, exigências quanto ao bom desempenho operacional e ambiental no manejo dos resíduos 
urbanos por parte dos municípios. Ela prevê que a responsabilidade do destino do lixo deve ser compartilhada entre todos que fazem parte do ciclo de vida dos produtos, incluindo fabricantes, importadores, distribuidores, comerciantes, consumidores e os responsáveis pelos serviços públicos de limpeza urbana.

Estabelece que o nível de prioridade, na gestão e gerenciamento de resíduos sólidos deve ser na seguinte ordem: não geração, redução, reutilização, reciclagem, tratamento dos resíduos sólidos e disposição final ambientalmente adequada dos rejeitos, determinando o direcionamento exclusivamente os rejeitos (somente aquilo que não pode mais ser reaproveitado ou reciclado) aos aterros sanitários legalizados, abolindo definitivamente o uso dos lixões como destino. Estabelece objetivos e diretrizes nacionais para resíduos sólidos, que dispõem sobre o que fazer e como fazer, objeto de interesse tratado neste texto. Encontram-se estabelecidos nos artigos 6 e 7 :

Art. $6^{0}$ São princípios da Política Nacional de Resíduos Sólidos:

I - a prevenção e a precaução;

II - o poluidor-pagador e o protetor-recebedor;

III - a visão sistêmica, na gestão dos resíduos sólidos, que considere as variáveis ambiental, social, cultural, econômica, tecnológica e de saúde pública;

IV - o desenvolvimento sustentável;

$\mathrm{V}$ - a ecoeficiência, mediante a compatibilização entre o fornecimento, a preços competitivos, de bens e serviços qualificados que satisfaçam as necessidades humanas e tragam qualidade de vida e a redução do impacto ambiental e do consumo de recursos naturais a um nível, no mínimo, equivalente à capacidade de sustentação estimada do planeta;

VI - a cooperação entre as diferentes esferas do poder público, o setor empresarial e demais segmentos da sociedade;

VII - a responsabilidade compartilhada pelo ciclo de vida dos produtos;

VIII - o reconhecimento do resíduo sólido reutilizável e reciclável como um bem econômico e de valor social, gerador de trabalho e renda e promotor de cidadania;

IX - o respeito às diversidades locais e regionais;

$\mathrm{X}$ - o direito da sociedade à informação e ao controle social;

XI - a razoabilidade e a proporcionalidade.

Art. $7^{\underline{o}}$ São objetivos da Política Nacional de Resíduos Sólidos:

I - proteção da saúde pública e da qualidade ambiental;

II - não geração, redução, reutilização, reciclagem e tratamento dos resíduos sólidos, bem como disposição final ambientalmente adequada dos rejeitos; 
III - estímulo à adoção de padrões sustentáveis de produção e consumo de bens e serviços;

IV - adoção, desenvolvimento e aprimoramento de tecnologias limpas como forma de minimizar impactos ambientais;

$\mathrm{V}$ - redução do volume e da periculosidade dos resíduos perigosos;

VI - incentivo à indústria da reciclagem, tendo em vista fomentar o uso de matériasprimas e insumos derivados de materiais recicláveis e reciclados;

VII - gestão integrada de resíduos sólidos;

VIII - articulação entre as diferentes esferas do poder público, e destas com o setor empresarial, com vistas à cooperação técnica e financeira para a gestão integrada de resíduos sólidos;

IX - capacitação técnica continuada na área de resíduos sólidos;

$X$ - regularidade, continuidade, funcionalidade e universalização da prestação dos serviços públicos de limpeza urbana e de manejo de resíduos sólidos, com adoção de mecanismos gerenciais e econômicos que assegurem a recuperação dos custos dos serviços prestados, como forma de garantir sua sustentabilidade operacional e financeira, observada a Lei $\mathrm{n}^{\circ} 11.445$, de 2007;

XI - prioridade, nas aquisições e contratações governamentais, para:

a) produtos reciclados e recicláveis;

b) bens, serviços e obras que considerem critérios compatíveis com padrões de consumo social e ambientalmente sustentáveis;

XII - integração dos catadores de materiais reutilizáveis e recicláveis nas ações que envolvam a responsabilidade compartilhada pelo ciclo de vida dos produtos;

XIII - estímulo à implementação da avaliação do ciclo de vida do produto;

XIV - incentivo ao desenvolvimento de sistemas de gestão ambiental e empresarial voltados para a melhoria dos processos produtivos e ao reaproveitamento dos resíduos sólidos, incluídos a recuperação e o aproveitamento energético;

XV - estímulo à rotulagem ambiental e ao consumo sustentável.

Ainda neste aspecto de orientações gerais, a Lei no 12.305, no artigo 8, I, determina como instrumento a criação de planos de resíduos sólidos como estímulo à implementação de infra-estruturas, estratégias e serviços capazes de pensar na problemática de forma integrada como um processo renovador e duradouro, que deve ser internalizado por todos os atores.

Uma vez entendida esta necessidade da ampla participação social, percebe-se que o fenômeno de uma única lei, por si só, não tem conseguido equacionar o problema da GRS. Para SILVA (2005), existem relações necessárias entre um conjunto de leis brasileiras que instituíram políticas públicas de desenvolvimento sustentável, consideradas leis irmãs, que 
permitem, justamente, conectadas a efetividade de uma lei para cumprimento de sua finalidade.

Dentre as quais podem ser citadas: Lei 9.433 de 1997, que institui a Política Nacional de Recursos Hídricos; Lei 10.257 de 2001, que institui o Estatuto das Cidades; Lei 8.080 de 1990, que dispõe das condições para promoção, proteção e recuperação da saúde; Lei 9.795 de 1999, que institui a Política Nacional de Educação Ambiental.

\subsection{Gestão de resíduos sólidos em instituições públicas}

Para construção de uma nova cultura institucional que estimule os gestores públicos a agregar critérios de gestão socioambiental para uma sociedade mais sustentável dentro de uma instituição é preciso seguir uma estratégia de planejamento. Esse sistema de gestão pode muito bem ser aplicado por meio da inserção de princípios e praticas de sustentabilidade socioambiental tendo como base a Agenda Ambiental na Administração Publica (A3P) norteada pela Política Nacional de Resíduos Sólidos.

A A3P é um programa do Ministério do Meio Ambiente que pretende instaurar um processo de construção de uma nova cultura institucional na administração pública, visando à inclusão de critérios socioambientais nos investimentos, compras e contratações de serviços pelo governo; combate a todas as formas de desperdício de recursos naturais e bens públicos; gestão adequada de todos os resíduos gerados e sensibilização dos servidores públicos em relação aos aspectos ambientais e de melhoria da qualidade do ambiente de trabalho.

Para a implementação da A3P, o MMA propõe a criação e regulamentação de uma comissão responsável pela Agenda na empresa, composto por servidores de várias áreas da instituição; a realização do diagnóstico da situação, identificando pontos críticos e avaliando os impactos ambientais e desperdícios gerados; a elaboração do planejamento integrado, envolvendo o maior número de colaboradores e áreas de trabalho; a definição de projetos e atividades, priorizando ações de maior urgência e relevância; a implementação das atividades programadas, realizando treinamentos e disponibilizando recursos físicos e financeiros; a avaliação e o monitoramento do desempenho ambiental, identificando avanços e deficiências; a busca de uma melhoria progressiva através da avaliação sistemática, do replanejamento, da introdução de novas tecnologias e da capacitação de funcionários. 


\subsection{Gestão de resíduos sólidos em instituições de ensino superior}

As instituições de ensino superior passaram a introduzir a temática ambiental em seus esquemas de gestão a partir dos anos sessenta, as primeiras experiências surgiram nos Estados Unidos, simultaneamente com as promoções de profissionais nas ciências ambientais.

O período entre as Conferências de Estocolmo em 1972 e do Rio de Janeiro em 1992, foi marcado pela emergência de envolvimento dessas instituições, na Declaração de Talloires, em outubro 1990, reitores e vice-reitores de universidades de várias regiões do mundo tornaram público seu interesse sobre a escala e a velocidade sem precedentes da poluição e da degradação ambiental. Estas mudanças ambientais ameaçam a sobrevivência dos seres humanos, dos milhares de outras espécies vivas, da integridade da terra, da sua biodiversidade, da segurança das nações e das gerações futuras. A declaração de Talloires, como é chamada no campus europeu em Talloires - França -, constatou ser fundamental dirigir ações urgentes a estes problemas para reverter as tendências atuais (THE TALLOIRES DECLARATION, 1990).

Um ano mais tarde, em dezembro de 1991 em Halifax, Canadá, representantes das universidades vinculadas à ONU e da associação das universidades e das faculdades do Canadá uniram-se com representantes das universidades de várias partes do mundo, a exemplo do Brasil, Indonésia e Zimbábue. A declaração de Halifax expressou seu desalento sobre a degradação disseminada e contínua do meio ambiente, das práticas ambientais insustentáveis, além do perverso aumento da pobreza (THE HALIFAX DECLARATION, 1991).

Em agosto 1993, na conclusão da conferência da associação das universidades comunitárias na Suécia, participantes de 400 universidades, de 47 países diferentes, focalizaram o tópico dos povos e do meio ambiente. A questão era encontrar maneiras de as universidades comunitárias, de seus líderes e de os estudantes acoplarem aos seus projetos metodologias para responder ao desafio da sustentabilidade. A reunião na Suécia, inspirada pelos exemplos de Talloires e de Halifax, e decepcionada pela fraca presença das universidades na Agenda 21, adicionou sua voz àquela mundial, que é concernida sobre a degradação do meio ambiente e do aumento da pobreza. Os participantes expressaram que as soluções a estes problemas serão eficazes no momento em que a vulnerabilidade de toda a 
sociedade for reconhecida e, as energias e as habilidades dos povos em toda parte, forem empregadas numa forma positiva e cooperativa (THE SWANSEA DECLARATION, 1993).

Desde então diversos compromissos inter e intra-universitários foram firmados, em resposta a busca pelo fortalecimento na atuação ambiental das universidades, orientando-as para a sustentabilidade. Pode-se exemplificar, atuações em redes, como a ARIUSA (Alianza de Redes Iberoamericana de Universidades por la Sustentabilidad y el Medio Ambiente), a ASPEA (Associação Portuguesa de Educação Ambiental), e a RUPEA (Rede Universitária de Programas de Educação Ambiental/Brasil).

Este movimento global das instituições de ensino superior evidencia a crescente busca por modelos de gestão ambiental para universidades. E no entendimento desta problemática específica percebeu-se que, os casos de gestão ambiental encontrados no mundo e no Brasil constituem, na maioria das vezes, práticas isoladas em situações em que a instituição já está implementada e funcionando. Esta situação revela a preocupação crescente de adaptação das universidades em busca de um desenvolvimento sustentável, não só no aspecto do ensino, mas de práticas de funcionamento ambientalmente corretas. Resgata-se então a importância da essência das universidades como laboratórios de idéias, espaços de fomento de novas perspectivas na busca de soluções para velhas problemáticas, que transcendam a aplicação de antigos modelos adaptados às novas realidades.

\section{ESTUDO DE CASO: IMPLANTAÇÃO DO NÚCLEO DE PROCESSAMENTO DE RESÍDUOS NA UNIVERSIDADE FEDERAL DE SANTA CATARINA}

É apresentada a seguir a experiência da UFS na busca por soluções que atendam aos requisitos legais e sejam exeqüíveis segundo as condições físicas, humanas e financeiras da instituição.

\subsection{A UFSC e os procedimentos de coleta de resíduos}

A Universidade Federal de Santa Catarina é composta por quatro campi distribuídos pelo Estado. O campus João David Ferreira Lima, situado no bairro Trindade, perímetro urbano da cidade de Florianópolis, é objeto de estudo desse artigo. 
A sede da Universidade Federal é divida em onze centros de ensino e ocupa área superior a 20 milhões de metros quadrados, com aproximadamente 40.000 pessoas, entre estudantes, funcionários e docentes.

É objetivo do estudo de caso do presente artigo, analisar as condições da atual coleta e destinação dos resíduos sólidos da UFSC para, a partir da formação de um núcleo interdisciplinar, estudar e diagnosticar os impactos diretos e significativos das problemáticas relacionadas a resíduos, com a finalidade de propor um plano de ação para melhoria contínua da gestão, baseada nos padrões da Política Nacional de Resíduos Sólidos.

\subsubsection{Resíduos orgânicos}

A coleta e tratamento de resíduos orgânicos na UFSC começou em 1995 a partir do Projeto "Compostagem de Resíduos Urbanos" após o diagnóstico dos resíduos gerados no campus, identificando os resíduos orgânicos como 50\% do total gerado no campus da UFSC (de Castilhos et al 1993). Progressivamente, novas fontes de resíduos orgânicos aumentaram a quantidade gerada na última década, todas absorvidas pelo projeto.

O projeto mantém bolsas a um grupo de oito estudantes da graduação, responsáveis pelo recolhimento e reciclagem dos resíduos orgânicos pelo processo de compostagem termofílica, orientados pelo professor Paul Richard Miller.

Segundo PITSCH (2011) a compostagem termofílica realizada na UFSC, é um processo controlado de decomposição aeróbia de resíduos orgânicos, realizada por microorganismos, principalmente fungos e bactérias. Os principais fatores, determinantes no processo, são os microorganismos aeróbicos, controle da umidade, aeração das leiras, controle da temperatura, relação carbono/nitrogênio do material de origem e dimensão adequada da leira. Todos esses elementos são indispensáveis para o processo de decomposição da matéria orgânica, dentro da leira fazendo com que as temperaturas atinjam entre $55^{\circ} \mathrm{C}$ a $65^{\circ} \mathrm{C}$. Isso faz com que ocorra a eliminação de patógenos e sementes de plantas daninhas, resultando em um fertilizante orgânico de alta qualidade e de baixo custo de produção.

Para firmar contrato com a UFSC, os bares e restaurantes devem adquirir e manter em bombonas de plástico com capacidade de 60 litros para o armazenamento dos resíduos orgânicos, conforme cláusula prevista em contrato. Atualmente, o projeto coleta e trata 64 toneladas de resíduos por mês, sendo indispensável um manejo adequado para que a 
compostagem ocorra de forma eficiente.

\subsubsection{Resíduos sólidos secos}

Atualmente, o processo de coleta de resíduos sólidos secos é o que mais apresenta problemas na UFSC. A forma de recolhimento, adotada pela Instituição, produz um ônus financeiro constante e crescente, sendo necessária uma urgente mudança de comportamento. A UFSC conta com vários contratos de prestação de serviços de remoção de resíduos, em virtude das especificidades das atividades de Ensino, Pesquisa e Extensão que exerce, e das dimensões territoriais que ocupa.

A ausência da coleta seletiva desencadeia uma série de problemas no campus. Os resíduos são dispostos misturados em contêineres, disponibilizados pela empresa contratada para a coleta dos mesmos. Materiais que poderiam ser reaproveitáveis, e conseqüentemente gerar renda, são descartados e levados ao aterro sanitário do município de Biguaçu.

Dentre os resíduos secos, os materiais que mais se destacam na UFSC são os papéis e os plásticos. O plástico é originado, em sua maior parte, nas lanchonetes e restaurantes do campus, e o papel, proveniente das atividades burocráticas e de ensino, nas salas de aulas e departamentos administrativos. A apropriação deste último material é feita pelas equipes de manutenção e limpeza da empresa terceirizada contratada, para comercialização. Os funcionários têm interesse nesse tipo de material pela quantidade, manuseio e facilidade de venda, descartando todo outro tipo de resíduo. Não há uma organização entre eles para a comercialização, o material é separado e armazenado em locais inapropriados, como salas vazias e banheiros, e posteriormente vendido cada um por si.

Dentre os principais desafios para implantação de uma gestão integrada de resíduos sólidos na UFSC destacam-se a falta de cultura ambiental na comunidade acadêmica, o desconhecimento da política ambiental pela comunidade universitária, a dificuldade de integração entre os órgãos administrativos, a deficiência de infraestrutura, além da falta de interesse dos integrantes da Universidade.

\subsection{O Núcleo de Processamento de Resíduos (NPR)}

\subsubsection{Objetivo Geral}

Pelas dimensões territorial e populacional da UFSC e pelo seu orçamento, comparável 
a grandes municípios do Estado, viu-se a necessidade de criar um núcleo próprio para o desenvolvimento de projeto visando a gestão adequada de resíduos sólidos na instituição, a fim de aderir à nova Política Nacional de Resíduos Sólidos.

O Núcleo de Processamento de Resíduos foi concebido no primeiro semestre de 2011 e é constituído por professores e alunos de diversos cursos da Universidade, além de servidores e funcionários.

\subsubsection{Objetivos Específicos}

O Núcleo é divido em dois grupos de trabalho. O primeiro deles para tratar das questões operacionais do gerenciamento de resíduos e o outro para atuar na área de pesquisa, desenvolvimento e inovação de tecnologias para a reutilização dos materiais.

São objetivos do NPR:

\subsubsection{Coleta seletiva solidária}

O NPR visa, como uma das prioridades, o manejo ambientalmente adequado de resíduos sólidos, através do plano e execução da coleta seletiva, proposta pelo Decreto Federal No. 5.940/2006. A coleta seletiva objetiva a separação dos resíduos recicláveis descartados pelos órgãos e entidades da administração pública federal direta e indireta, na fonte geradora, e a sua destinação às associações e cooperativas dos catadores de materiais recicláveis.

Pelo artigo $2^{\circ}$, considera-se:

“Art. 2: I - coleta seletiva solidária: coleta dos resíduos recicláveis descartados, separados na fonte geradora, para destinação às associações e cooperativas de catadores de materiais recicláveis; e

II - resíduos recicláveis descartados: materiais passíveis de retorno ao seu ciclo produtivo, rejeitados pelos órgãos e entidades da administração pública federal direita e indireta."

A coleta seletiva oferece melhores condições de aproveitamento dos resíduos, por evitar a contaminação como, por exemplo, com os resíduos biodegradáveis tais como restos de comida, cascas de frutas e verduras, entre outros, que em um curto espaço de tempo, decompõem-se e produzem odor desagradável, podendo atrair animais propagadores de doenças. Outro aspecto relevante dessa prática é o estimulo à cidadania pela participação por 
toda comunidade universitária. Permite ainda a redução do volume de resíduos a serem dispostos, contribuindo para a economia dos recursos da Universidade.

Mais um motivo para a adesão ao sistema de coleta seletiva foi firmado no início de 2010. O Governador de Santa Catarina proibiu, através da Lei Estadual 15.112/2010, o despejo de resíduos recicláveis em lixões e aterros sanitários e previu sanções, sendo o infrator sujeito às seguintes penalidades de acordo com o Art. $3^{\circ}$ :

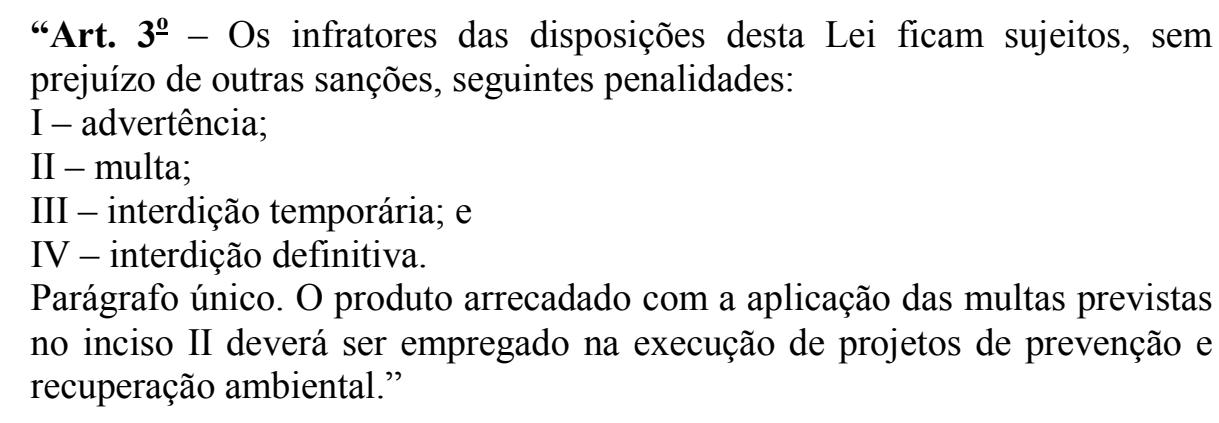

Para essa etapa do processo de implantação ser concretizada é necessária a sensibilização e capacitação técnica e operacional de execução das atividades pela Prefeitura do Campus em parceria com as empresas terceirizadas que efetuam o serviço de limpeza e conservação. O NPR objetiva estabelecer um programa de treinamento e orientação dos terceirizados e da comunidade em relação a disposição adequada dos resíduos de acordo com a classificação a ser definida pelo programa de gerenciamento integrado de resíduos elaborado pelo grupo de trabalho específico.

Aparentemente esta segregação pode parecer insuficiente, porém, os resíduos sólidos biodegradáveis (orgânicos) são responsáveis por mais da metade desse total. Entende-se assim, que, para o primeiro momento, de implantação da segregação parcial, o fato dos resíduos secos não serem misturados com os orgânicos já garante outra qualidade dos resíduos para o seu aproveitamento, valorizando o material quando for vendido pela cooperativa. Os resíduos que, depois esgotadas todas as possibilidades de tratamento e recuperação, serão destinados à coleta comum pela empresa vinculada à Prefeitura de Florianópolis.

\subsubsection{Educação ambiental}

Para implantar a coleta seletiva na cidade universitária, faz-se necessária a 
conscientização de seus membros para que percebam a necessidade e incorporem mudanças em seus comportamentos. Nesse sentido é de fundamental importância o trabalho permanente da educação ambiental, a partir do efetivo envolvimento dos atores públicos e institucionais e da população que reqüenta a UFSC, entre funcionários terceirizados, servidores, alunos e professores.

Segundo SILVA (1998), o Desenvolvimento Sustentável é muito mais que um modelo, um estilo de desenvolvimento e, enquanto tal, necessita ser compreendido e incorporado ao mundo que cada pessoa constrói, em seu domínio de condutas, com as demais pessoas com quem convive. A Educação Ambiental surge, então, como um esforço pedagógico de articular conhecimentos, metodologias e práticas ditadas pelo paradigma da sustentabilidade. O que esta proposição teórica nos permite afirmar é que a Educação Ambiental pode ser vista como a estratégia inicial do Desenvolvimento Sustentável através da qual as pessoas não só se qualificam, mas se sensibilizam para reencontrar suas pertinências e afinidades com a natureza e o Universo, ponto de partida substantivo do paradigma da sustentabilidade.

A construção da pertinência dos cidadãos universitários com o campus através de um plano de educação ambiental tem-se como primordial, uma vez que a atual relação desses indivíduos com os resíduos que geram, sua consciência de responsabilidade da geração até o destino final, está intimamente ligada ao nível da indiferença causada por esta desconexão com o território da universidade.

\subsubsection{Constituição de cooperativa de reciclagem}

O NPR pretende criar mecanismos de inclusão social através de incentivos e preferência a cooperativas de catadores formado por pessoas de baixa renda, integrantes da empresa terceirizada responsável pela limpeza do campus. No Decreto $\mathrm{n}^{\mathrm{o}} 7.404$, que regulamenta a lei 12.305, existe um claro apoio às cooperativas formadas por pessoas de baixa renda como podemos observar no texto do Artigo 40:

"Art. 40. O sistema de coleta seletiva de resíduos sólidos e a logística reversa priorizarão a participação de cooperativas ou de outras formas de associação de catadores de materiais reutilizáveis e recicláveis constituídas por pessoas físicas de baixa renda." 
Tem-se como primeiro passo para a constituição da cooperativa, identificar as pessoas envolvidas na geração e recolhimento informal dos resíduos, para posteriormente firmar no contrato da UFSC com a empresa contratada o adicional da participação dos agentes de limpeza na coleta e separação dos resíduos.

\subsubsection{Compostagem de resíduos orgânicos}

Cerca de $50 \%$ dos resíduos gerados na Universidade são provenientes do material orgânico produzido nos restaurantes universitários, hospital, colégio e lanchonetes. Diante destes dados percebemos a importância da compostagem como forma de reduzir custos operacionais, além de contribuir, através da doação do composto produzido para o campus inteiro, escolas públicas municipais (Projeto Horta Viva) e parques em Florianópolis.

Pela Lei 12.305, a compostagem aparece como uma ferramenta, que visa possibilitar destinação ambientalmente adequada dos resíduos sólidos como menciona o Inciso VII, do Art. $3^{\circ}$ :

"Art. $3^{\circ}$ Para os efeitos desta Lei, entende-se por:

VII - destinação final ambientalmente adequada: destinação de resíduos que inclui a reutilização, a reciclagem, a compostagem, a recuperação e o aproveitamento energético ou outras destinações admitidas pelos órgãos competentes do Sistema, do SNVS e do Suasa, entre elas a disposição final, observando normas operacionais específicas de modo a evitar danos ou riscos à saúde pública e à segurança e a minimizar os impactos ambientais adversos;"

Ainda no Art. $3^{\circ}$, a reciclagem aparece como "um processo de transformação dos resíduos sólidos que envolve a alteração de suas propriedades físicas, físico-químicas ou biológicas, com vistas à transformação em insumos ou novos produtos...”. Isto nos permite concluir que a parcela orgânica dos resíduos sólidos é passível de reciclagem, a partir da técnica da compostagem.

A compostagem, apesar de ser considerada uma ferramenta para diminuir os impactos ambientais dos resíduos, também necessita de licenças ambientais para funcionar, no que diz respeito ao local para disposição dos resíduos. Em 2011 o NPR conseguiu, a partir da mudança do pátio de compostagem para o Itacorubi, a Certidão de Regularidade junto a FATMA (Fundação do Meio Ambiente), no 195729/2011.

Com o uso de técnicas apropriadas, a compostagem pode tornar-se um grande aliado para ajudar a minimizar a fração orgânica dos resíduos da universidade, aliviando o já 
saturado aterro sanitário de Biguaçu que recebe os resíduos de Florianópolis e região.

\subsubsection{Pesquisa e extensão}

Faz parte do projeto a criação de um grupo especializado para atuar no desenvolvimento de novos produtos, novos processos e máquinas para o processamento dos resíduos, tendo como foco principal a reutilização de materiais e a extração de energia por biodigestores. Esse grupo será formado por alunos e professores da Engenharia de Materiais, a partir da criação de um Programa de Educação Tutorial (PET).

É de interesse dos integrantes do NPR a criação de um ambiente multidisciplinar visando a aproximação de especialistas da área e estudantes, a fim de desenvolver técnicas e projetos alinhados aos objetivos do núcleo.

\subsubsection{Legislação e fiscalização}

Um dos pontos importantes do projeto é resolver as questões pendentes da UFSC no que se refere ao atendimento da legislação ambiental. A fiscalização de todo o processo de gestão, além da coleta dos rejeitos realizada pela empresa contratada pela universidade, será realizada pela Prefeitura do campus.

\section{2.2.7 Divulgação e informação}

Para que a comunidade universitária se sinta parte integrante do plano de gestão dos resíduos sólidos, é fundamental que seja informado sobre os acontecimentos e análises do processo. O trabalho da educação ambiental para a conscientização dos integrantes da Universidade tem que ser contínuo, já que há uma alta rotatividade de pessoas que frequentam o campus durante os semestres.

\section{CONCLUSÃO}

Diante da priorização da não geração de resíduos, estabelecida pela Política Nacional dos Resíduos Sólidos, propôs-se uma estratégia que envolva a comunidade universitária de modo qualificado para sua participação no planejamento e na gestão deste bem comum, ou seja, o resíduo como responsabilidade compartilhada. 
Os benefícios de uma gestão integrada de resíduos sólidos são muitos e, entre eles, se destacam as economias pelo melhoramento da produtividade e da redução no consumo de energia, água e materiais de expediente; o estabelecimento das conformidades com a legislação ambiental, reduzindo assim, os riscos de incorrer em penalidades ou gerar passivos ambientais; a evidência de práticas responsáveis e melhora na imagem externa da instituição; e a geração de oportunidades de pesquisa.

Cabe ainda dizer que o presente trabalho reforça a importância de uma abordagem interdisciplinar para o enfrentamento da problemática, conduzindo o processo de gestão integrada de resíduos sólidos em universidades por uma valorização de experiências, em torno do qual serão buscadas as melhores práticas, as melhores políticas e os melhores resultados, visando errar, gastar e perder menos, incluir, distribuir e poupar mais. Diante disso, vem a valorização da experiência local e internacional, emergindo a reflexão sobre o que realmente vale a pena no processo.

\section{BIBLIOGRAFIA}

ABNT (ASSOCIAÇÃO BRASILEIRA DE NORMAS TÉCNICAS). Classificação de resíduos sólidos: NBR 10.004. Rio de Janeiro, 2ª Ed. 2004.

ALMEIDA, J.R. Gestão Ambiental: planejamento, avaliação, implantação, operação e verificação/ Josimar Ribeiro de Almeida, Yara Cavalcanti, Cláudia dos S. Mello - Rio de Janeiro: Thex Ed., 2000.

BRASIL. Decreto n. ${ }^{\circ} 5.940$, de 25 de outubro de 2006, Institui a separação dos resíduos recicláveis descartados pelos órgãos e entidades da administração pública federal direta e indireta, na fonte geradora, e a sua destinação às associações e cooperativas dos catadores de materiais recicláveis, e dá outras providências. Diário Oficial [da] Republica Federativa do Brasil, Brasília, DF.

BRASIL. Lei . $^{\circ} 12.035$, de 2 de agosto de 2010. Institui a Política Nacional de Resíduos Sólidos; altera a Lei no 9.605, de 12 de fevereiro de 1998; e dá outras providências. Diário Oficial [da] Republica Federativa do Brasil. Brasília, DF.

FIGUEIREDO, P.J.M. A sociedade dolixo. Piracicaba: Editora Hemus, 2 ed.,1995.

INSTITUTO BRASILEIRO DE GEOGRAFIA E ESTATÍSTICA - IBGE, Pesquisa Nacional de Saneamento Básico - 2008. Rio de Janeiro, 2010.

LIMA, J. D. Gestão de resíduos sólidos urbanos no Brasil. Rio de Janeiro: ABES, 2001. $267 \mathrm{p}$. 
MESQUITA JÚNIOR, J.M. Gestão integrada de resíduos sólidos / José Maria de Mesquita Júnior. Coordenação de Karin Segala. - Rio de Janeiro: IBAM, 2007.

MMA - Ministério do Meio Ambiente. Agenda Ambiental na Administração Pública. Disponível em http://www.mma.gov.br Acesso em 20 de setembro de 2011.

MONTEIRO, José Henrique Penido [et al.] Manual de Gerenciamento Integrado de resíduos sólidos / Coordenação técnica Victor Zular Zveibil. Rio de Janeiro: IBAM, 2001.

MORENO, E., \& POL, E. Nociones psicosociales para la intervención y lagestión ambiental (Monografies Socio / Ambientals, 14). Barcelona:Publicacions Universitat de Barcelona, 1999.

PITSCH, Eduardo Ferreira. A Gestão de resíduos sólidos na UFSC e sua adequação frente às novas regras da Política Nacional de Resíduo Sólido (lei 12.305/2010). Trabalho de Conclusão de Curso - Centro de Ciências Agrárias. Florianópolis: Universidade Federal de Santa Catarina, 2011.

PORTILHO, Maria de Fátima Ferreira. Profissionais do lixo: um estudo sobre as representações sociais de engenheiros, garis e catadores. Dissertação de mestrado Programa EICOS. Rio de Janeiro: Universidade Federal do Rio de Janeiro, 1997. Relatório Brundtland - Nosso Futuro Comum/ Comissão Mundial sobre Meio Ambiente e Desenvolvimento. 2. Ed. Rio de Janeiro: Editora da Fundação Getúlio Vargas, 1991. XVIII, $430 \mathrm{p}$.

SANTA CATARINA. Lei n. ${ }^{\circ} 15.112$, de 19 janeiro de 2010. Dispõe sobre a proibição de despejo de resíduos sólidos reaproveitáveis e recicláveis em lixões e aterros sanitários. Diário Oficial do Estado de Santa Catarina - Assembléia Legislativa de Santa Catarina.

Florianópolis.

SCHENINI, P. C. (Org) Gestão empresarial socioambiental. Florianópolis: (s.n.), 2005.

SILVA, D. J. O Complexo como uma Episteme Transdisciplinar. In: AMÂNCIO FRIAÇA, Luiza; et al. Educação de Transdisciplinaridade III. São Paulo: TRIOM, 2005.

SILVA, D. J. Uma abordagem cognitiva ao planejamento estratégico do desenvolvimento sustentável. Tese de Doutorado. Programa de Pós-Graduação em Engenharia de Produção Florianópolis - Universidade Federal de Santa Catarina, 1998.

[SMA] SÃO PAULO (ESTADO). SECRETARIA DE ESTADO DE MEIO AMBIENTE. Proposta de Política Estadual de Resíduos Sólidos. São Paulo (SP): Secretaria de Estado de Meio Ambiente [Série Documentos Ambientais]; 1998B.

TAUCHEN, Joel and BRANDLI, Luciana Londero. A gestão ambiental em instituições de ensino superior: modelo para implantação em campus universitário. Gest. Prod. [online].

Rev. GUAL., Florianópolis, v. 4, n. 3, p.170-193, set/dez. 2011 
2006, vol.13, n.3, pp. 503-515. ISSN 0104-530X.

TEIXEIRA, Murilo.(Tese) Mestrado em Sistema de Gestão - Laboratório de Tecnologia, Gestão de Negócios e Meio Ambiente - LATEC. Rio de Janeiro: Universidade Federal Fluminense, (s/d).

THE HALIFAX DECLARATION, 1991. Disponível em:

http://www.iisd.org/educate/declarat/halifax.htm. Acesso em 28 de outubro de 2011.

THE SWANSEA DECLARATION, 1993. Disponível em:

http://www.iisd.org/educate/declarat/swansea.htm. Acesso em 28 de outubro de 2011.

THE TALLOIRES DECLARATION, 1990. Disponível em:

http://ulsf.org/programs talloires.html. Acesso em 28 de outubro de 2011.

ZANTA, V.M.; FERREIRA , C.F.A. Gerenciamento Integrado de Resíduos Sólidos

Urbanos. In: BORGES , A.C. EL AL (Org). Resíduos sólidos urbanos: Aterro Sustentável para Municípios de Pequeno Porte. 1 ed. São Carlos SP: Rima Artes e Textos , v.1., 2003. 


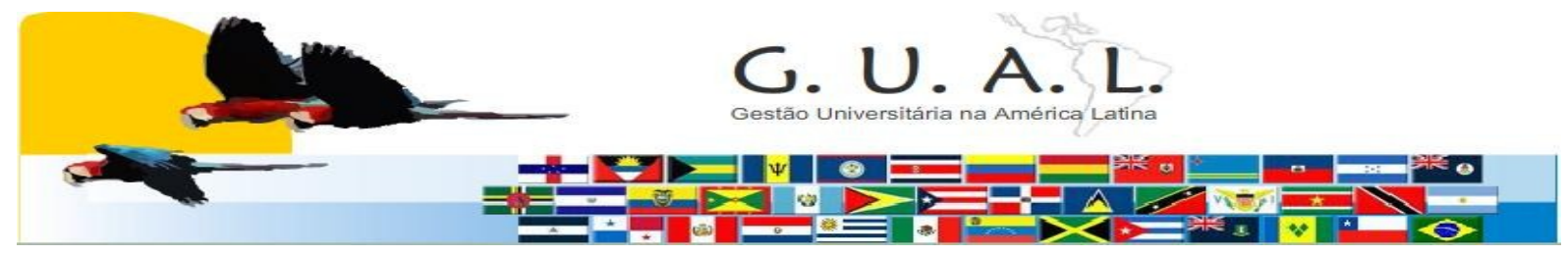

ISSN 1983-4535

\title{
INTEGRATED SOLID WASTE MANAGEMENT FOR PUBLIC INSTITUTIONS OF HIGHER EDUCATION
}

\author{
Dante Luiz Juliatto, Doctor \\ Universidade Federal de Santa Catarina \\ dante.juliatto@.ufsc.br \\ Milena Juarez Calvo, Bachelor \\ Universidade Federal de Santa Catarina \\ milenajuarez@hotmail.com \\ Thaianna Elpídio Cardoso, Bachelor \\ Universidade Federal de Santa Catarina \\ thaiannacardoso@gmail.com
}

\begin{abstract}
This paper presents a discussion of the solid waste problem of the recent Federal Law $12.305 / 2010$, the proposed tools for managing in public institutions and how this clash has occurred in public universities and organs of its administration. It aims to propose a systematization of integrated procedures, from a complex view of this specific situation. The realization of the case study at Federal University of Santa Catarina culminates to consolidate a management model that will adjust to the current legislation, allowing them to adapt to the culture of sustainability. To this end, we discuss the fundamental role of universities as a laboratory of ideas in the constant search for solutions, combined with other laws for sustainable development.
\end{abstract}

Keywords: Integrated management. Solid waste. Public institutions. Universities. 